\title{
A review of stabilization methods for DCMG with $C P L$, the role of bandwidth limits and droop control
}

\author{
Sarah Ansari ${ }^{1 *}$ (D, Jing Zhang ${ }^{1}$ and Rajat Emanuel Singh ${ }^{2}$
}

\begin{abstract}
DC microgrids (DCMGs) integrate and coordinate various DC distribution generation units including various renewable energy sources and battery storage systems, and have been used in satellites, the International Space Station, telecom power stations, computer power supplies, electric aircraft, and electric ships. However, the presence of constant power loads (CPLs) can cause instability in DCMGs. Thus, this paper reviews the stabilization techniques that can resolve instability caused by CPLs, as well as various parameters of CPLs, such as bandwidth, and the frequency of the CPLs that can stabilize the DCMGs. It also discusses recent trends and future work in finding stability limits using the parameters of CPLS. It should be useful for directing research towards appropriate mathematical and experimental approaches for the stability of DCMGs with CPLs.
\end{abstract}

Keywords: DC microgrids, DC distribution generation units, Stability, Constant power loads, Bandwidth

\section{Introduction}

The generation, transmission, and distribution of power can use alternating current (AC) or direct current (DC). Conventional power systems are inherently $\mathrm{AC}$ power systems. However, many renewable energy sources are DC power sources, so they cannot be integrated directly into AC power systems. Therefore, for renewable energy sources, DC power systems can potentially be more beneficial than $\mathrm{AC}$ power systems. In addition, there is no reactive power and reactive loss involved in DC power systems. This results in reduced cost of cables and improved efficiency of the systems. Moreover, DC power systems allow ease of power transfer from one frequency to another (e.g., from 60 to $50 \mathrm{~Hz}$ or vice versa). Therefore, there has been increased exploration of DC power systems and their wider applications.

\footnotetext{
*Correspondence: sxansari@ualr.edu

${ }^{1}$ Engineering and Information Technology, University of Arkansas, Little Rock, Little Rock, USA

Full list of author information is available at the end of the article
}

Despite their advantages pertinent to renewable energy sources, DC power systems exhibit certain limitations with distributed generation (DG) units. In a DC power system with various DG units connected, various issues arise including voltage fluctuation and power mismatch between DG units. These could lead to entire system instability. Thus, there is a need to aggregate DG units and provide proper coordination among them.

Microgrids integrate and coordinate different DG units and provide solutions for DG integration problems. The Consortium for Electric Reliability Technology Solutions (CERTS) in the USA defines a microgrid as "An aggregation of loads and micro- sources operating as a single system providing both power and heat" [1-3]. DC microgrids (DCMGs) have seen increased application as they integrate and coordinate renewable energy sources, energy storage systems, and other DG units. However, with the involvement of diverse DG units, poor coordination between them arises leading to potential instability. For example, DCMGs with hybrid energy storage systems (HESS) have stability issues and various strategies are adopted to regulate the voltage and to stabilize 
the system. Reference [4] discusses the semi-consensus strategy of HESS in DCMG, and the proposed strategy can not only regulate voltage-droop with integral- droops but also enable the recovery of DC bus voltage so as to stabilize the DCMG.

The DG units can be coordinated effectively with the use of power electronic converters within the microgrid. These power converters are present at the source side and the load side of the DCMG, and their control parameters can be voltage, current, power, etc. [5, 6]. However, some power electronic converters have limitations because of their innate characteristics which can add further instability to the system, and in particular, the tightly regulated load side power converters when behaving as constant power loads (CPLs). Moreover, the issue of stability is aggravated when the converters are cascaded to each other [7].

This paper reviews various stabilization techniques that can overcome instability due to the non-linearity of CPLs. The CPLs and the cause of their inherent non-linear phenomena are discussed and recent research looking at practical CPLs and its significance are addressed. Finally, the role of bandwidth limit and droop control in being deciding factors for stability are discussed. A complete summary of the introduction is illustrated in Fig. 1.
The novelty of this review paper is the inclusion of stabilization techniques focused particularly on CPLs and the significance of practical CPLs, while previous reviews discuss the stabilization techniques without clearly defining the stages at which these approaches are to be applied.

\section{CPLs in a distribution system}

To understand the innate non-linear characteristics of a CPL that lead to instability, it is important to know how a load side converter acts as a CPL in DCMG. A DC distribution system has two stages of power converter interface as shown in Fig. 2 [8]. The first stage consists of source-side power converters while the second stage consists of load-side power converters. The source-side converters are also called line regulating converters (LRCs) as they regulate the voltage supplied to the DC bus, whereas the load-side power converters are also called point of load converters (POLs) that are connected to the various loads. During operation, the POLs behave as CPLs [8].

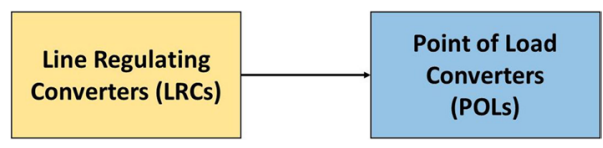

Fig. 2 Power converter interface stages of DC distribution system

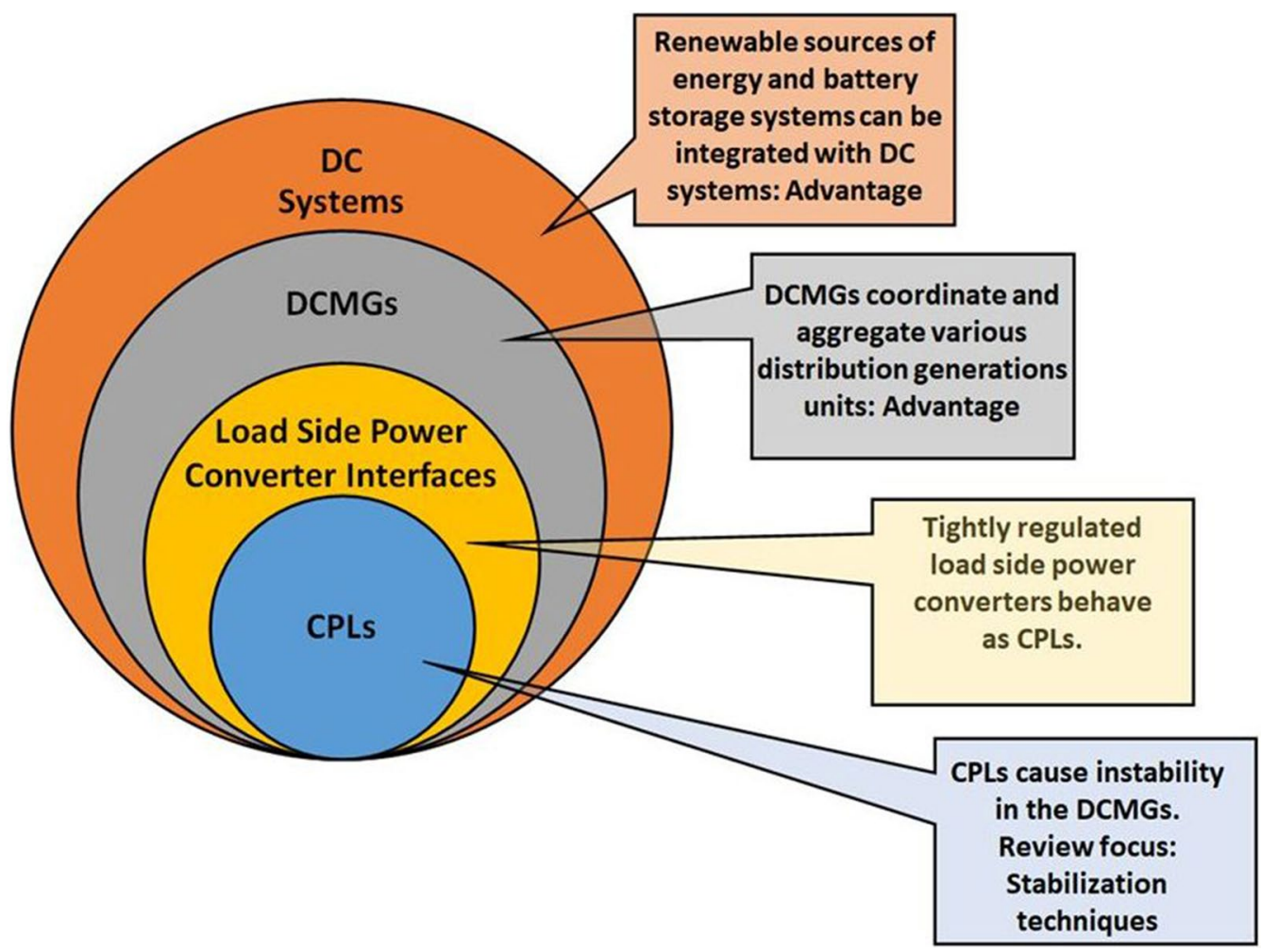

Fig. 1 Summary of introduction 
LRCs and POLs can be implemented on various topologies such as the buck, boost, or buck-boost, etc. Among them, buck converters are widely employed as they have higher system stability and DC gain than other types of converters [9].

\section{$3 \mathrm{CPL}$ and its linearization}

\subsection{Characteristics of CPL}

CPL shows non-linearity due to an inverse relationship between its voltage and current as shown in Fig. 3. The main characteristic of a CPL is the negative incremental impedance, since the constant power of a CPL means its output voltage varies inversely with respect to the current. Such a negative incremental impedance characteristic of a CPL causes a destabilizing effect in the DC distribution system, whereas a resistive load does not result in negative incremental impedance (Fig. 3).

In [10], CPLs are compared with resistive loads to distinguish between their different characteristics. This is important in discovering the additional restrictions levied on the applied control solution. Reference [8] shows how the dynamic behavior of a converter connected to a resistive load is different from that of a converter connected to a CPL. The dynamics of resistive load and CPL are compared through derivation of line-to output and control-to output transfer functions, which are derived in current-controlled and voltage-controlled modes. Simulation results indicate that the system is unstable in continuous conduction mode (CCM) but stable in discontinuous conduction mode (DCM) when the voltage-controlled mode is applied. Further, both CCM and DCM constitute an unstable open loop in the current-controlled mode. These varying outputs in different modes illustrate the varying dynamic behavior of the converter connected to CPLs.

\subsection{Linearization of CPL}

To overcome the instability caused by the non-linear behavior of CPLs, it is important to linearize the CPLs. From Fig. 3, CPLs also exhibit instantaneous positive impedance around which they are linearized. A constant power $P$ is assumed at which the system is linearized. For such a small time interval, it can be approximated as a line, and the average current $(i)$ with respect to average voltage $(v)$ is given as [11]:

$$
i=\frac{P}{v}
$$

At a given operating point, the rate of change of average current with respect to average voltage is given as:

$$
\frac{d i}{d \nu}=-\frac{P}{V^{2}}
$$

Using the above equation and drawing a tangent of the curve at a point, we give a straight line with the following description with $V$ being the steady-state voltage, as:

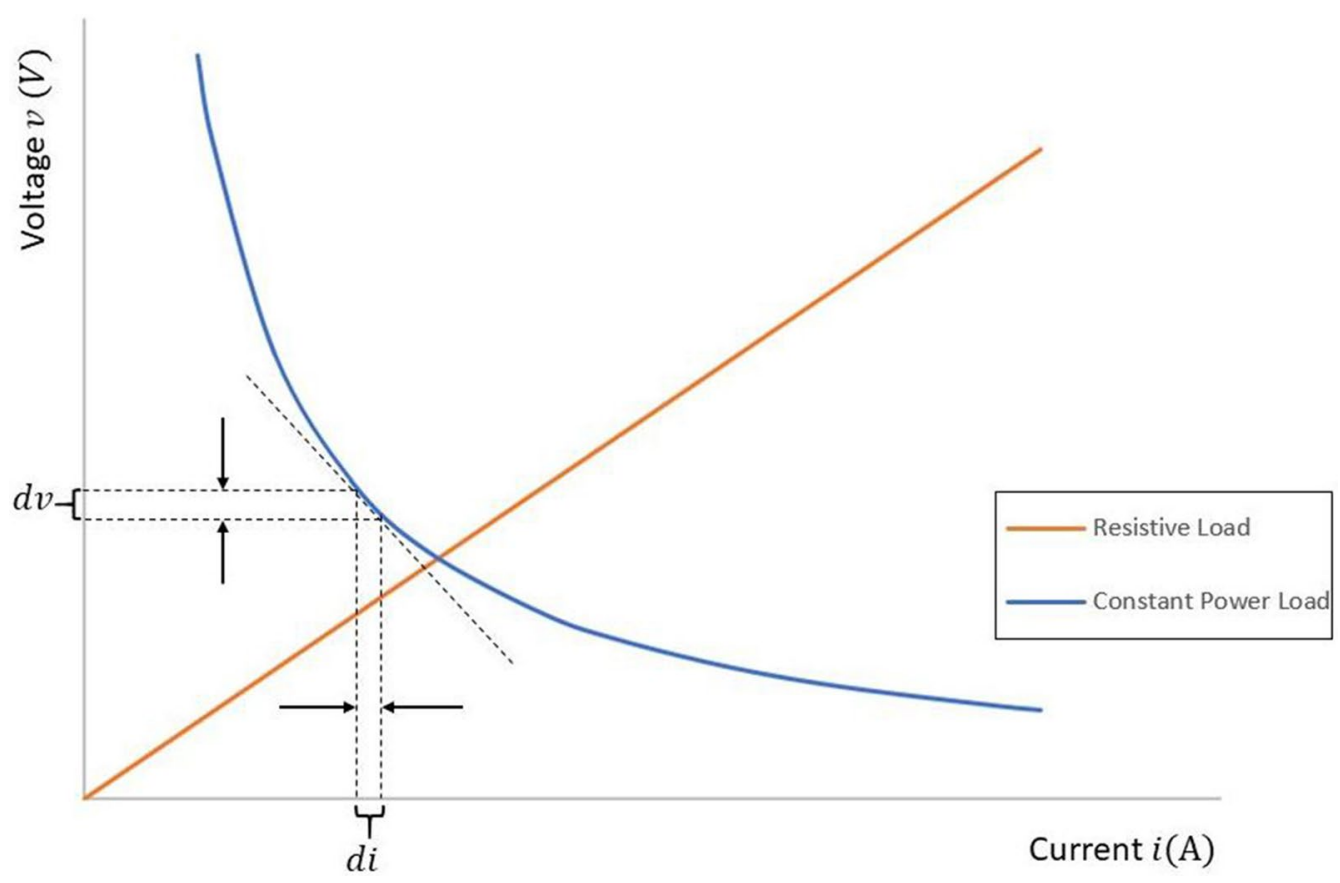

Fig. 3 Voltage-current characteristics of resistive load and CPL 


$$
i=-\frac{P}{V^{2}} v+2 \frac{P}{V}
$$

The above equation linearizes the non-linear model of a CPL at a predefined operating point. Thus, the CPL can be approximated as a combination of negative resistance connected in parallel to a constant current source [11],

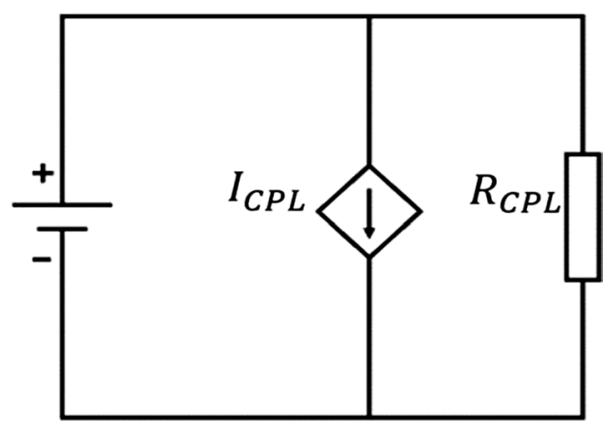

Fig. 4 Equivalent resistor and current source

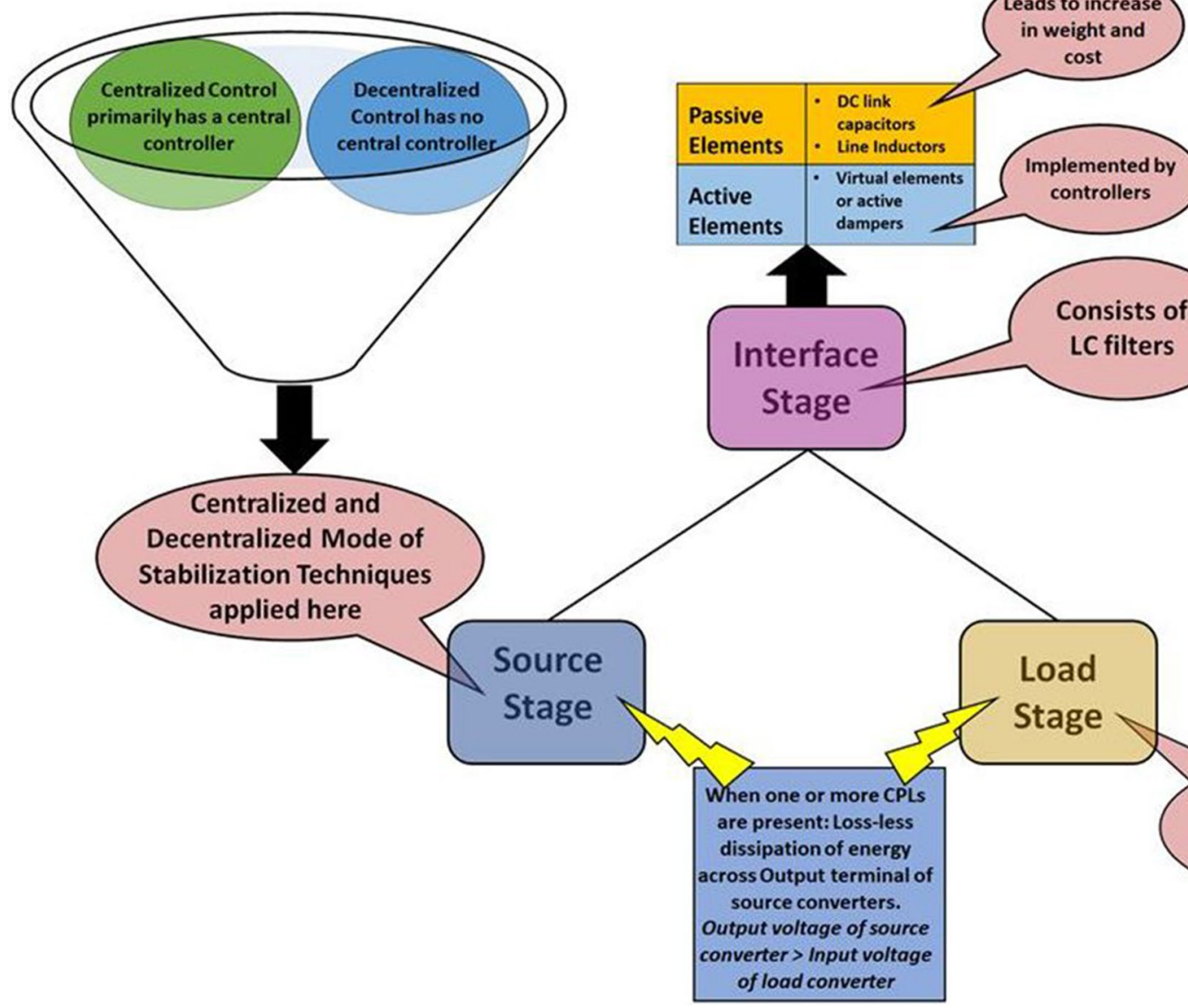

as shown in Fig. 4. This is generally a common approach taken by researchers and is also employed in the average modeling method. However, stabilization is not restricted to linearizing the CPLs.

\subsection{Impacts due to non-linearity of CPLs}

In this section, two major stability issues that impact the DCMGs because of the non-linearity of CPLs are presented. The first issue occurs when either one or more CPLs exist in the DCMGs, as shown in Fig. 5, while the second issue occurs when multiple CPLs are present with multiple resistive loads.

For the first issue, the negative incremental impedance of a CPL causes damping in the system (Fig. 5), leading to lossless dissipation of energy across the output terminals of the source converters. This results in a low input voltage at the CPL compared to the output of the source voltage. Hence, because of a voltage mismatch between the CPL and the source converter, the system is not able to return to its equilibrium state. Furthermore, both the

Fig. 5 Detailed description of 3 stabilization stages of DCMGs 
power quality and system reliability are affected by the negative incremental impedance of the CPL [12].

The second stability issue arises when multiple resistive loads and CPLs are connected in parallel. In such a case, when the number of resistive loads is greater than the CPLs, the voltage of the load bus oscillates [13]. This leads to limit cycle behavior with an unstable equilibrium point. As a result, the energy of the source converter oscillates between the capacitor and inductor leading to instability of the system [13, 14]. Reference [13] discusses such a condition and through simulated and experimented studies, a solution by designing a closed-loop control of the entire system is provided.

\section{Stabilization techniques for CPL}

There are usually three stages in a DCMG consisting of CPLs as shown in Fig. 5 [15], including: (1) The source stage comprising various power converters that supply regulated voltage to the DC bus. (2) The interface stage where the LC filter is used to stabilize the CPL and smooth the voltage waveform. (3) The load stage consisting of load converters connected to loads. These three stages can be modified independently to stabilize the DCMG, and the stabilization techniques are classified as source-side, interface, and load-side stabilization techniques.

The source-side and load-side techniques are widely covered in the literature. The implementation of both can be done either using passive damping methods that employ additional passive elements in the system or by introducing virtual inductors, capacitors, or resistors (as shown in Fig. 5) [11, 13, 15-18]. Passive elements like DC link capacitors or line inductors can contribute to system stability but lead to increased weight and cost (Fig. 5) [17]. Thus, it is not practicable to implement passive damping methods. On the other hand, virtual elements or active dampers can be virtually introduced by various controllers (Fig. 5).

Load-side had been studied earlier than source-side techniques, e.g., a virtual resistor [11] and a virtual capacitor [17] were used to compensate for the destabilizing nature of CPLs. Although these active dampers (virtual resistors, virtual capacitors, etc.) can be implemented at the load-side, the injected power can significantly affect the load performance [16]. Thus, it is considered that a source-side strategy is preferable to a load-side strategy since it does not affect the load performance by changing the source dynamics [16]. From the communication point of view, source-side stabilization can be classified into centralized, decentralized and distributed modes (shown in Fig. 5). The modes will be discussed in detail in Sect. 5.

\subsection{Non-linear methods}

Various non-linear techniques have been studied such as sliding mode control, synergetic control, feedback linearization, backstepping control, and passivity-based control (PBC), as illustrated in Fig. 6.

The sliding mode technique [19-23] has been extensively studied because of its fast dynamic response, robustness, and simplicity of the circuit [24]. However, it is often employed on constant resistive loads or where system load characteristics are not considered. In addition, it exhibits a chattering problem. Thus, a new sliding mode control technique is proposed in [24] and is employed on a three-phase rectifier in DC systems. The technique is responsible for the voltage regulation and mitigation of the instability impact of CPLs. However, sliding mode control employs derivatives that cannot compensate for the non-linearity in the presence of noise [25].

In contrast, feedback linearization involves a linear feedback path to cancel the nonlinearity of the system [26]. Novel non-linear feedback under the feedback linearization category can be applied to all converters

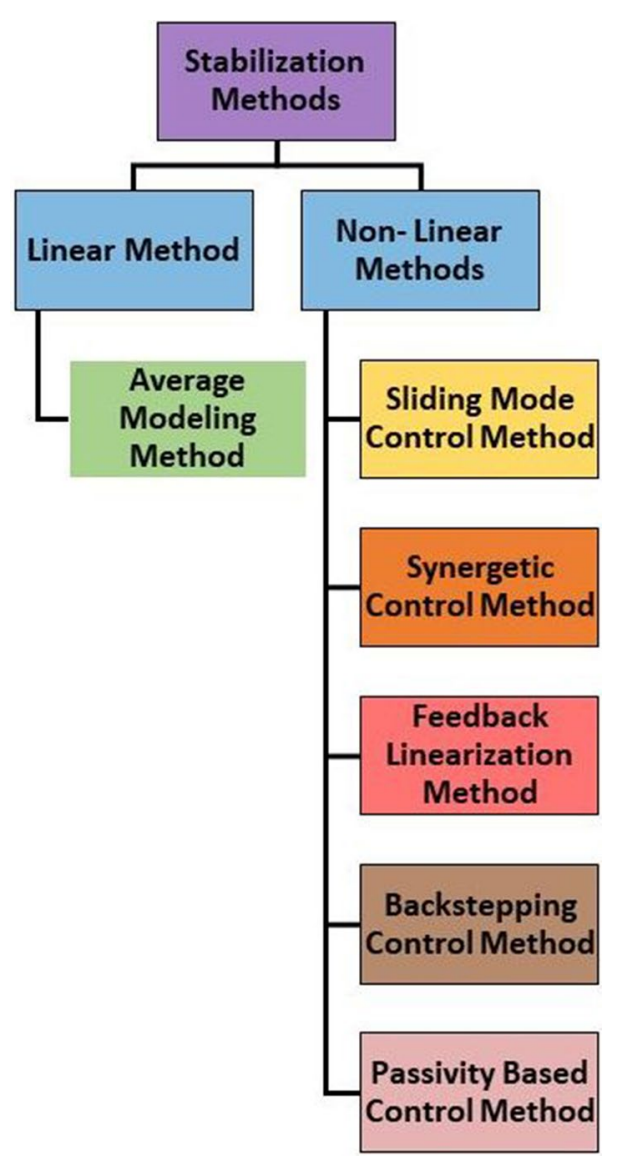

Fig. 6 Linear and non-linear stabilization methods 


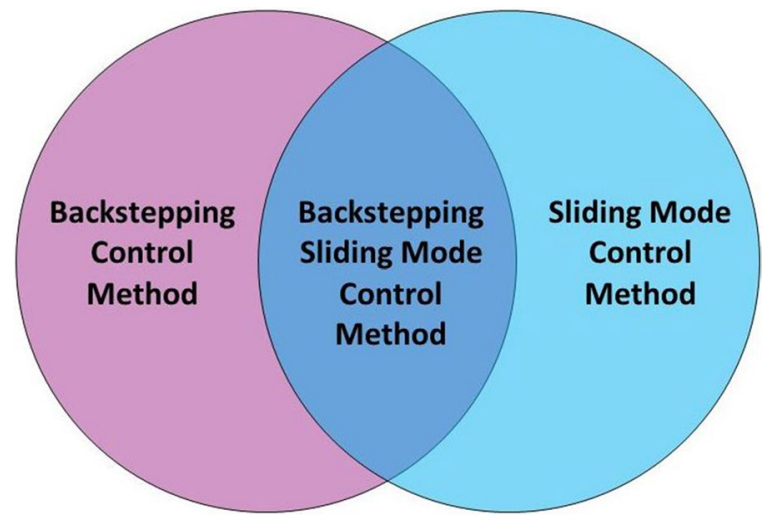

Fig. 7 Venn diagram of backstepping sliding model strategy

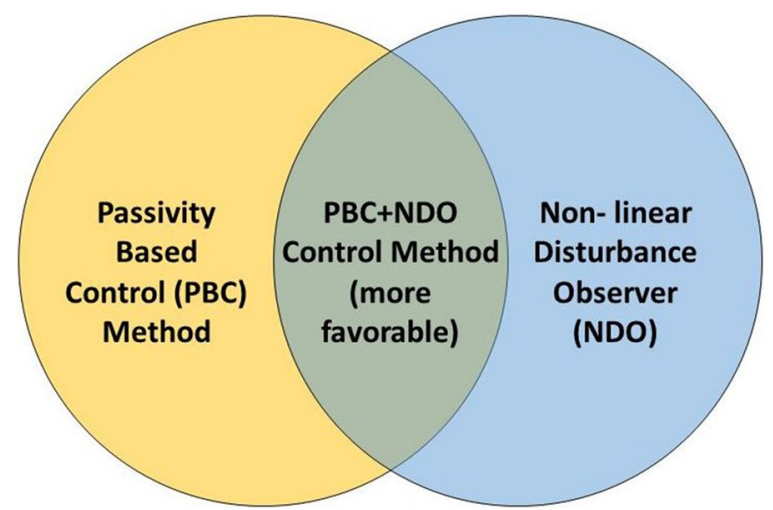

Fig. 8 Venn diagram of PBC + NDO model strategy

including CPLs in CCM. Theoretically, it can compensate for any number of CPLs and adjust the damping of the system. This is useful, particularly before designing the feedback of the controller [26], while [27] considers it a follow-up of input-output linearization of a boost converter with a mixed load.

The adaptive backstepping sliding mode control strategy, as shown in Fig. 7, has been generally used to stabilize the boost converter connected to CPLs [12]. This method is a non-linear method with exact feedback linearization and backstepping sliding mode control, and has been found to be more advantageous than the exact feedback linearization method [27].

While other non-linear methods are important depending on the use, $\mathrm{PBC}$ is proven to be the most effective non-linear method [13]. However, the disturbances caused by source and load variations cannot be compensated for using solely the PBC method. Hence, the method is modified to include both $\mathrm{PBC}$ and a nonlinear disturbance observer (NDO) as shown in Fig. 8. This is discussed for closed-loop control in [28]. Another non-linear phenomenon called bifurcation has also been studied and analyzed extensively. The various bifurcation parameters can be load power [29-31], feedback gain [32, 33], capacitance [33], load resistance [33, 34], inductance [35], parasitic resistance of the inductor, switching frequency [36], gain controller [37, 38], compensating ramp [38-40], the series resistance of the capacitor [41], input voltage, current reference, etc.

\subsection{Small-signal and large-signal stability approaches}

Load-side and source-side control methodologies employ either a small-signal or a large-signal stability approach. In the case of small-signal stability analysis, the dynamic performance is governed by an operating point, whereas large-signal analysis determines a region of equilibrium (ROE) in the system. Using the small-signal method to stabilize open-loop converters is investigated in [42]. However, small-signal stability has some limitations. First, the dynamic characteristics of the system are neglected, and hence it cannot assist in the study of stability margin [43]. Secondly, small-signal analysis employs a continuous-time average or averaged model that neglects the impact of switching frequency and thus can only be used when the switching frequency is much larger than the cut-off frequency of the LC filter [18, 44], e.g., 10 times larger as indicated in [45]. Thus, large-signal stabilization techniques must be devised and employed as CPLs are non-linear, time-dependent, and have negative instability issues. Reference [46] introduces large-signal phase plane analysis to efficiently apply power electronics converters and motor drives in automotive systems, while [47] proposes a compound stabilizer to realize large-signal stabilization of DCMG with CPLs. The proposed stabilizer in [47] used a non-linear approach like NDO and backstepping controller to stabilize the floating dual mode boost converters (FDBC) and CPLs. The simulation results prove that the proposed controller gives a broader stability margin for the FDBCs as compared to other controllers such as the PI controller. Finite-time observers (FTOs) and a finite-time controller are proposed in [48], and large-signal stabilization is realized through the proposed observers and controller for DCMGs with CPLs. The results prove that the proposed stabilization has a wider stability margin than conventional controllers.

\section{Control hierarchy of DCMGs}

DCMGs have a control hierarchy which is divided into three levels, i.e., primary, secondary, and tertiary. Reference [49] analyzes all the levels extensively and discusses the flexibility of the hierarchal structure. The various stabilization modes, i.e., centralized, decentralized, and distributed (to be discussed in Sect. 5) can be applied to more than one level of control. 


\subsection{Primary control}

This control level deals with power-sharing among various DG units in the DCMG. It is strictly local within the DG units [50]. The control bandwidth of this level is the highest (in $\mathrm{kHz}$ ) of the three levels [50]. The technique requires good physical communication links between various units which leads to increased complexity in large microgrids. Centralized and decentralized modes of stabilization are applied to the primary level of control, while droop control is the most commonly used strategy at the primary level [51]. Recent research focuses on improving the reliability of primary control. Decentralized voltage controllers are introduced in the primary level of the control in [49] to improve reliability and provide flexibility to the DCMGs.

\subsection{Secondary control}

This control level aims at regulating the deviations in DC bus voltage caused by the primary droop control. Secondary control can be integrated within the DG units or with tertiary control [50]. When integrated within the DG units, it is called the distributed mode whereas, when integrated with the tertiary control with a central controller, it is called the centralized mode [50]. Both the centralized and distributed modes of stabilization have been extensively studied. The focus of the studies is to integrate diverse DG units (like various energy storage systems, renewable energy sources, etc.) and provide stability to the entire DCMG. Reference [52] discusses how cyber-physical implementation can improve secondary control and develops a consensus algorithm to regulate the DC bus voltage and overcome the issues caused by primary droop control.

\subsection{Tertiary control}

Tertiary control is employed so that the DC bus voltage can be synchronized with the DCMGs. The tertiary controller compares the DC bus voltages at the DG units with the standard bus voltage [50]. When the difference in the voltage values is within the threshold, a bypass switch is turned on [50]. This signals a complete synchronization of DC bus voltage with the DCMG. The optimal references generated at the tertiary control are discussed in [49]. These are aided by the integration of energy management systems to the DGMG. Reference [49] also shows how the integration of new DG units (energy management systems) can govern tertiary control. This level of control is also responsible for power management between microgrids and upper-level grids, thus coordinating them to provide a holistic energy management system [50].

\section{Modes of stabilization}

As mentioned in Sect. 3, the source side stabilization can be implemented in centralized or decentralized mode. Also, the control hierarchy, as discussed in Sect. 4, designates the hierarchy level to which the modes of stabilization should be applied.

\subsection{Centralized mode of stabilization}

In addition to active dampers, the centralized control mode also employs sliding mode control, the global stabilization method, model predictive control, feedback linearization, backstepping, and synergetic control. These methodologies are non-linear and will be discussed later. However, a centralized mode performs communication with various power sources, hence requiring sensors to be located at various places of the microgrid. The arrangement of additional sensors makes this type of mode less favorable because of the higher cost. In [17], it proposes removing all these sensors and employing a state observer to estimate the missing state data using given inputs and outputs [17]. This type of control strategy is called a decentralized mode and is preferred to a centralized mode.

\subsection{Decentralized mode of stabilization}

Many strategies employ a decentralized mode of control. Droop control is a commonly used one that obtains proper power sharing for the source converters [15]. This control also employs non-linear methods that have been mentioned previously. Reference [16] discusses a virtual negative inductor that is connected at the end of the source side converter and is based on droop control strategy. The virtual negative inductor can counteract the large line inductance which becomes dominant with the introduction of CPLs. However, the introduction of the virtual negative inductor results in undesired highfrequency noise which has to be filtered using a low pass filter.

\subsection{Distributed mode of stabilization}

The distributed mode of stabilization involves communications between the primary, secondary, and tertiary levels of control systems. This mode of has also evolved over the years. Because of its high reliability, resilience, and scalability, it is regarded as more suitable than the centralized mode. Global information can easily be shared in this mode, while recently, the Internet of Things (IoT) has enabled great progress in research on the distributed mode. In [53], a novel distributed control scheme for microgrids using the IoT paradigm is proposed. This defines the multiagent systems (MAS) that exchange information to control the microgrid and enable its smooth functioning. However, new challenges to 
this model arise when the MAS has to deal with CPLs, and thus more work is required. In this mode of stabilization, communication analysis is also important as the units can be scattered in a network. Reference [54] successfully analyzes the effect of communication changes in the distributed mode of DCMGs, and it concludes that the communication delay between the control hierarchies does not cause steady-state error, but it reduces the damping of the system. Destabilization, however, can still occur because of the presence of CPLs. Further research and hardware experimentation are required to stabilize DCMG with CPLs in the distributed mode.

\section{Frequency indicators to determine strategy for stabilization}

LC filters are the fundamental components of power converters. The relationship between the LC filter resonant frequency and switching frequency plays an important role in determining the control strategy for stabilization. When there is a substantial difference between the two frequencies (e.g., the switching frequency being at least 10 times greater than the resonant frequency [55]), the average modeling method is employed for stabilization [56].

However, in some systems, when the switching and resonant frequencies become comparable, average modeling methods cannot be employed for stabilization. Instead, discrete time-sampled modeling methods have to be used. For example, systems such as transportation have weight and cost constraints, and thus embedded components are employed [55]. As a result, the passive components ( $\mathrm{L}$ and $\mathrm{C}$ ) are reduced, which leads to an increase in the resonant frequency. Hence the resonant frequency becomes comparable to the switching frequency. Then a non-linear system at a faster timescale must be introduced to develop a discrete time-sampled modeling method, as used in [57] for a boost converter. The Monodromy matrix is presented to provide information on various parameters of the boost converter so as to investigate how external parameters can influence the performance of the converter. The Filippov method is further applied to the boost converter system to conduct stability analysis and control nonlinear phenomena [57]. However, the study does not consider CPL, and therefore further research is needed to incorporate the non-linear behavior of the CPL for stability analysis.

Reference [58] focuses on small and large signal simulation analysis of two cascaded buck converters, with considerations of the switching frequency, bandwidth, and power levels of the two converters. The buck converter at the load side behaves as an ideal CPL and has a switching frequency higher than the converter at the source side [58]. In this way, a more realistic CPL behavior is achieved. It concludes that by considering the frequency parameters of the LRCs and POLs, one can achieve the CPL behavior (for POL) and devise stabilization techniques for the entire DCMG [58].

\section{Significance of practical CPLs}

Research largely considers ideal CPLs to devise various stabilization techniques, and conventionally a theoretical framework using ideal CPLs has been used. However, there are limitations to such a theoretical approach, as the interdependency of control parameters of power converters at the source and load sides is not taken into consideration. Since these parameters are not considered, it is assumed that CPLs cause instability of the system at all times and bandwidths. However, there are certain instances of time and bandwidth where practical CPLs do not lead to instability. Therefore, it becomes imperative to choose practical over ideal CPLs.

In [42], various parameters like input voltage range, efficiency, feedback loop gains, and bandwidth, and how they help implement practical CPLs, are discussed. The study concludes that above a certain minimum input level, a tightly regulated closed-loop converter behaves as a CPL, while by increasing the damping of the LC filter, the open-loop system with CPL can be stabilized [42]. This work has been further extended in [58], where it proves mathematically and through simulation the interdependence between the controller parameters of POL and LRC. It concludes that there is a bandwidth limit for which even practical CPLs behaving ideally do not cause instability to the system. The significance of the paper lies in the fact that it verifies that ideal CPLs, despite their non-linearity, can still stabilize the system, provided there are certain constraints on them.

\section{Bandwidth of CPLs}

The literature has mostly considered high bandwidth load converters to study the stabilization of the system. Recent studies have emphasized the importance of the bandwidth of controlled-load converters. The relationship between system stability and bandwidth of controlledload converters is established in [59] by considering a system consisting of cascaded DC-DC converters. The correlation between the bandwidths of the converters at the load side and voltage regulation is determined [59, 60], and the developed relation is important for determinin the bandwidth limit above which system stability can be compromised. The work has been extended in [61], where the DC-DC cascaded converter is converted into a fifth-order system to validate the analysis of the reduced third-order system. It concludes that the approximated third-order system is valid and is more effective than the fifth-order system. This enables the reduction of 
system complexity while maintaining the dynamic performance of the system, thereby making it flexible for scalability.

In [62], the same approach is extended to Modular Multilevel Converters (MMC) in MVDC electrical distribution systems that supply CPLs with limited bandwidth. The MMC control structure proposed in [62] consists of two controls, one for capacitor voltage and the other for circulating current. In addition, the control structure also consists of a phase-locked loop (PLL). With such a detailed source-side MMC controller, the stability analysis is carried out on the system having bandwidth-limited CPLs. It concludes that DC voltage control, horizontal and vertical energy balancing, circulating and line currents control affect the source side impedance, while the $\mathrm{MMC}$ as a source-side converter offers good stability to the entire system with bandwidth-limited CPLs. In addition, the bandwidth range of CPLs also plays an important role in stabilizing the DCMG with CPLs.

With the cascaded DC-DC converter system, in addition to the linearization of the system, a Lure System is created in [63], in which the input signal is the output voltage from the source side converter and the outputs are the duty cycle, input, and output voltages of the load side converters. The Lure System has 3 forward blocks and one feedback block. The forward block transfer functions determine the duty cycles of the load side converters and the output voltages of the load side and the source side converters, while the feedback block gives the value of the output voltage of the MVDC bus [63]. The scheme facilitates stability assurance by deriving a generalized frequency behavior of the system. The analysis, however, concludes that the control frequency must not exceed the resonance frequency of the filters [63].

\section{Droop control with practical CPLs}

Droop control, as described in the above sections, is the most commonly used decentralized mode of control in practical multigrid systems [64-67]. It has two main benefits: 1) Its implementation facilitates proper load sharing among various source converters without any communication with the load side converters; and 2) Mathematical analysis on the models having droop control is simple.

Few papers have discussed the interdependency of the source side and load side converter parameters when the source side uses droop control. Moreover, study on practical CPLs and source converters with droop control is limited. As the transition from ideal CPLs to practical CPLs is more credible, the interaction between practical CPLs and droop control on the source side offers a more realistic model for stabilization, as presented in [68-70]. A model of a DC system having multiple sources and loads is considered to emulate future, more electric, aircraft (MEA). The basis of the analysis is the impedances of the parallel sources and multiple loads, while the papers draw some interesting conclusions related to the converter parameters and the droop gain.

Although ideal CPLs do not exist, they are emulated for experimental purposes. Therefore, several studies focus on emulating CPLs. A CPL is emulated through Chroma DC electronic load, and the transducer is used in LabVIEW with SPI communication to transfer the data from DSP to the desktop computer [71]. In [27], a CPL is emulated using GW Instek PEL- 3031E programmable DC electronic load, whereas in [72], a Programmable Load Chroma Model 63,210 is employed to emulate a CPL along with dSPACE DS1006 for generating PWM signals. While such implementation of CPLs has been used extensively in previous research, construction of an analog CPL (A-CPL) that can emulate CPL is proposed in [73]. This is cost-effective and offers a fast response. However, the A-CPL is not quite practical especially when there is manual switching between different modes. Also, it can implement only one type of load at a time [74]. Another implementation is through a Norton amplifier as mentioned in [75], but it also has the same drawback of not being able to change the load dynamically. A digital implementation of constant power, current, and voltage loads is proposed in [74], and in the case of a CPL, the circuit configuration is the same as that in an A-CPL, but instead of manually changing the current value, a DSP processor is used. The proposed implementation also offers scalability, and when high constant power, current, or voltage loads are required the cells, which consist of Bipolar Junction Transistors (BJTs) and resistors in series, can be added. However, care must be taken on the discrepancies arising due to variations of BJTs and sense resistors. Although the above-mentioned CPL implementations have proven to be effective for laboratory work, they have not been physically presented in a real DCMG.

\section{Conclusion and future work}

This paper has examined various stabilization techniques that are mostly based on ideal CPLs to account for their negative incremental impedance nature. The techniques discussed are either implemented on the source or load side of the DCMGs. Different linearization and non-linear methods have been categorized, and specific control methods for different stages of DCMGs have also been presented. Techniques from the communication point of view, i.e., centralized, decentralized, and distributed modes of control have been discussed together with recent research on the advance in non-linear control strategies. Active and passive damping methods employed at the interface stage are also discussed. Although passive damping methods are 
undesirable, various controller design methods to compensate for the instability may not be practically feasible because of their lack of generality. Recent research in this field is primarily focused on working with the parameters of the CPLs and deriving an interdependency between the source and load side converters.

The techniques and methods developed so far have limited scope. Research is needed to devise advanced techniques so that the stability issue of DCMGs with CPLs can be resolved, e.g., in the hierarchical control of DCMGs to accommodate CPLs and stabilize the entire system. Some studies have focused on the effect of bandwidth of the CPLs on system stability and have devised the limits for which CPLs may not cause instability despite being ideal. However, there has not been a practical implementation of such a system. Similarly, research conducted on the system with droop control and CPL is application-specific and non-generic. Thus there is scope for research on the stability of practical and generic systems having CPLs, governed by droop control. Research on DCMGs with practical CPLs is important as they are now extensively used in various applications, such as in the International Space Station, electric vehicles, undersea and other naval vessels.

\begin{abstract}
Abbreviations
DCMG: DC microgrid; CPL: Constant power loads; DG units: Distributed generation units; CERTS: Consortium for electric reliability technology solutions; HESS: Hybrid energy storage systems; LRC: Line regulating converter; POL: Point of load converter; CCM: Continuous conduction mode; DCM: Discontinuous conduction mode; PBC: Passivity-based control; NDO: Non-linear disturbance observer; ROE: Region of equilibrium; FDBC: Floating dual mode boost converters; FTO: Finite-time observers; loT: Internet of things; MAS: Multiagent systems; MMC: Modular multilevel converters; MEA: More electric aircraft.
\end{abstract}

\section{Acknowledgements}

The authors are grateful to College of Engineering and Information Technology, University of Arkansas, Little Rock, USA for providing necessary facilities to carry out the work. The authors are also grateful to Barry Ellis (M.S. Systems Engineering, University of Arkansas, Little Rock), currently working as a Construction Engineer at Entergy Arkansas LLC, for his editing and constructive criticism of the manuscript.

\section{Authors' contributions}

"The first author (SA) surveyed the literature, arranged it systematically and produced the draft of MS. The second author (JZ) supervised the work as research guide. The third author (RES) corrected and suggested some changes in the draft manuscript. All authors read and approved the final manuscript."

\section{Funding}

Not applicable.

\section{Availability of data and materials}

Not applicable.

\section{Declarations}

\section{Competing interests}

The authors declare that they have no known competing financial interests or personal relationships that could have appeared to influence the work reported in this paper.

\section{Author details}

${ }^{1}$ Engineering and Information Technology, University of Arkansas, Little Rock, Little Rock, USA. ${ }^{2}$ Northwestern College, Orange City, lowa, USA.

Received: 27 January 2021 Accepted: 25 November 2021

Published online: 06 January 2022

\section{References}

1. Lasseter, R. H. (2002). Microgrids. In Proceedings of the IEEE POWER ENGINEERING SOCIETY WINTER MEETING (pp. 305-308).

2. Lasseter, R., Akhil, A., Marnay, C., Stephens, J., Dagle, J., Guttromson, R., Meliopoulos, A., Yinger, R., \& Eto, J. (2017).

3. Martin-Martínez, F., Sánchez-Miralles, A., \& Rivier, M. (2016). A literature review of Microgrids: A functional layer-based classification. Renewable and Sustainable Energy Reviews, 62, 1133-1153.

4. Lin, P., Zhao, T., Wang, B., Wang, Y., \& Wang, P. (2020). A semi-consensus strategy toward multi-functional hybrid energy storage system in DC microgrids. IEEE Transactions on Energy Conversion, 35(1), 336-346. https:// doi.org/10.1109/TEC.2019.2936120

5. Luo, S. (2005). A review of distributed power systems part I: DC distributed power system. IEEE Aerospace and Electronic Systems Magazine, 20, 5-16.

6. Fulwani, D. K., \& Singh, S. (2016). Mitigation of negative impedance instabilities in DC distribution systems: A sliding mode control approach. Springer.

7. Du, W., Zhang, J., Zhang, Y., \& Qian, Z. (2013). Stability criterion for cascaded system with constant power load. IEEE Transactions on Power Electronics, 28, 1843-1851.

8. Grigore, V., Hatonen, J., Kyyra, J., \& Suntio, T. (1998). Dynamics of a buck converter with a constant power load. In Power electronics specialists Conf. (29th Annual IEEE 1, 17-22).

9. Rim, C. T., Joung, G. B., \& Cho, G. H. (1988). A state space modeling of nonideal dc-dc converters. In IEEE power electronics specialists conf. rec (pp. 943-950).

10. Rivetta, C., \&Williamson, G. A. (2004). Global behaviour analysis of a DCDC boost power converter operating with constant power load. Proceedings of International Symposium on Circuits and Systems, 5, 956-959.

11. Rahimi, A. M., \& Emadi, A. (2009). Active damping in DC/DC power electronic converters: A novel method to overcome the problems of constant power loads. IEEE Transactions on Industrial Electronics, 56, 1428-1439.

12. Arora, S., Balsara, P., \& Bhatia, D. (2019). Input-output linearization of a boost converter with mixed load (constant voltage load and constant power load). IEEE Transactions on Power Electronics, 34, 815-825.

13. Hassan, M. A., Li, E. P., Li, X., Li, T., Duan, C., \& Chi, S. (2019). Adaptive passivity-based control of DC-DC buck power converter with constant power load in DC microgrid systems. IEEE Journal of Emerging and Selected Topics in Power Electronics, 7, 2029-2040.

14. Kwasinski, A., \& Onwuchekwa, C. N. (2011). Dynamic behavior and stabilization of DC microgrids with instantaneous constant-power loads. IEEE Transactions on Power Electronics, 26, 822-834.

15. Lu, X., Sun, K., Guerrero, J. M., Vasquez, J. C., Huang, L., \&Wang, J. (2015). Stability enhancement based on virtual impedance for DC microgrids with constant power loads. IEEE Transactions on Smart Grid, 6, 2770-2783.

16. Liu, S., Su, P., \& Zhang, L. (2018). A virtual negative inductor stabilizing strategy for DC microgrid with constant power loads. IEEE Access, 6 , 59728-59741.

17. Magne, P., Nahid-Mobarakeh, B., \& Pierfederici, S. (2013). Active stabilization of DC microgrids without remote sensors for more electric aircraft. IEEE Transactions on Industry Applications, 49, 2352-2360.

18. Mazumder, S. K., Nayfeh, A. H., \& Boroyevich, D. (2001). Theoretical and experimental investigation of the fast- and slow-scale instabilities of a DC-DC converter. IEEE Transactions on Power Electronics, 16, 201-216.

19. Sabanovic, A., \& Šabanović, N. (2008). Sliding modes applications in power electronics and electrical drives. https://doi.org/10.1007/3-54045666-X_10.

20. Mishra, R., Hussain, M. N., \& Agarwal, V. (2016). A sliding mode control based stabilization solution for multiple constant power loads with identical input filters interfaced with the DC bus of a 'More Electric' Aircraft. In 2016 IEEE international conference on power electronics, drives and energy 
systems (PEDES), Trivandrum, 2016, (pp. 1-6). https://doi.org/10.1109/ PEDES.2016.7914300.

21. Martínez-Treviño, B. A., Aroudi, A. E., \& Martínez-Salamero, L. (2018). Synthesis of constant power loads using switching converters under sliding mode control. In 2018 IEEE international symposium on circuits and systems (ISCAS), Florence, 2018 (pp. 1-5). https://doi.org/10.1109/ISCAS.2018.83514 35

22. Zhao, Y., Qiao, W., \& Ha, D. (2014). A sliding-mode duty-ratio controller for DC/DC buck converters with constant power loads. IEEE Transactions on Industry Applications, 50(2), 1448-1458. https://doi.org/10.1109/TIA.2013. 2273751

23. Anderson Azzano, J. L., Moré, J. J., \& Puleston, P. F. (2019). Stability criteria for input filter design in converters with CPL: Applications in sliding mode controlled power systems. Energies, 12, 4048. https://doi.org/10. 3390/en12214048

24. Zhang, M., Li, Y., Liu, F., Luo, L., Cao, Y., \& Shahidehpour, M. (2017). Voltage stability analysis and sliding mode control method for rectifier in DC systems with constant power loads. IEEE Journal of Emerging and Selected Topics in Power Electronics, 5, 1621-1630.

25. Bosich, D., Giadrossi, G., \& Sulligoi, G. (2014). Voltage control solutions to face the CPL instability in MVDC shipboard power systems. In Proceedings of AEIT Annual (pp. 1-6).

26. Rahimi, A. M., Williamson, G. A., \& Emadi, A. (2010). Loop-cancellation technique: A novel nonlinear feedback to overcome the destabilizing effect of constant-power loads. IEEE Transactions on Vehicular Technology, $59,650-661$.

27. $\mathrm{Wu}$, J., \& Lu, Y. (2019). Adaptive backstepping sliding mode control for boost converter with constant power load. IEEE Access, 7, 50797-50807.

28. Hassan, M. A., Li, T., Duan, C., Chi, S., \& Li, E. P. (2017). Stabilization of DC-DC buck power converter feeding a mixed load using passivity-based control with nonlinear disturbance observer. In Proceedings of IEEE conference on energy internet energy systems integration (E/2) (pp. 1-6).

29. Gavagsaz-Ghoachani, R., Martin, J. P., Pierfederici, S., Nahid-Mobarakeh, B., \& Davat, B. (2013). DC power networks with very low capacitances for transportation systems: dynamic behavior analysis. IEEE Transactions on Power Electronics, 28, 5865-5877.

30. Saublet, L. M., Gavagsaz-Ghoachani, R., Martin, J. P., Nahid-Mobarakeh, B., \& Pierfederici, S. (2016). asymptotic stability analysis of the limit cycle of a cascaded DC-DC converter using sampled discrete-time modeling. IEEE Transactions on Industrial Electronics, 63, 2477-2487.

31. Xia, C., Song, P., \& Shi, T. (2013). Chaotic dynamics characteristic analysis for matrix converter. IEEE Transactions on Industrial Electronics, 60, 78-87.

32. Aroudi, A. E., Orabi, M., Haroun, R., \& Martinez-Salamero, L. (2011). Asymptotic slow-scale stability boundary of PFC AC-DC power converters: Theoretical prediction and experimental validation. IEEE Transactions on Industrial Electronics, 58, 3448-3460.

33. Orabi, M., \& Ninomiya, T. (2003). Nonlinear dynamics of power-factor-correction converter. IEEE Transactions on Industrial Electronics, 50, 1116-1125.

34. Sha, J., Xu, J., Bao, B., \& Yan, T. (2014). Effects of circuit parameters on dynamics of current-mode-pulse-train-controlled buck converter. IEEE Transactions on Industrial Electronics, 61, 1562-1573.

35. Pantic, Z., Bai, S., \& Lukic, S. (2011). ZCS-compensated resonant inverter for inductive-power-transfer application. IEEE Transactions on Industrial Electronics, 58, 3500-3510.

36. Xie, F., Zhang, B., \& Yang, R. (2013). Detecting bifurcation types and characterizing stability in DC-DC switching converters by duplicate symbolic sequence and weight complexity. IEEE Transactions on Industrial Electronics, 60, 3145-3156.

37. Dranga, O., Buti, B., \& Nagy, I. (2003). Stability analysis of a feedbackcontrolled resonant DC-DC converter. IEEE Transactions on Industrial Electronics, 50, 141-152.

38. Aroudi, A. E. (2017). A new approach for accurate prediction of subharmonic oscillation in switching regulators-Part II: Case studies. IEEE Transactions on Power Electronics, 32, 5835-5849.

39. Aroudi, A. E., Rodríguez, E., Leyva, R., \& Alarcón, E. (2010). A design-oriented combined approach for bifurcation prediction in switched-mode power converters. IEEE Transactions on Circuits and Systems II: Express Briefs, 57, 218-222.

40. Gavagsaz-Ghoachani, R., Nahid-Mobarakeh, B., Pierfederici, S., Zandi, M., Davat, B., Martin, J. P., \& Phattanasak, M. (2015). Estimation of the bifurcation point of a modulated-hysteresis current-controlled DC-DC boost converter: Stability analysis and experimental verification. IET Power Electronics, 8, 2195-2203.

41. Wang, J., Bao, B., \& Xu, J. (2013). Dynamical effects of equivalent series resistance of output capacitor in constant on-time controlled buck converter. IEEE Transactions on Industrial Electronics, 60, 1759-1768.

42. Rahimi, A. M., \& Emadi, A. (2009). An analytical investigation of DC/DC power electronic converters with constant power loads in vehicular power systems. IEEE Transactions on Vehicular Technology, 58, 2689-2702.

43. Zadeh, M. K., Gavagsaz-Ghoachani, R., Martin, J. P., Pierfederici, S., NahidMobarakeh, B., \& Molinas, M. (2017). Discrete-time tool for stability analysis of DC power electronics-based cascaded systems. IEEE Transactions on Power Electronics, 32, 652-667.

44. Gavagsaz-Ghoachani, R., Saublet, L. M., Phattanasak, M., Martin, J. P., Nahid-mobarakeh, B., \& Pierfederici, S. (2018). Active stabilisation design of DC-DC converters with constant power load using a sampled discrete-time model: Stability analysis and experimental verification. IET Power Electronics, 11, 1519-1528.

45. Saublet, L. M., Gavagsaz-Ghoachani, R., Martin, J. P., Nahid-Mobarakeh, B., \& Pierfederici, S. (2016). Bifurcation analysis and stabilization of DC power systems for electrified transportation systems. IEEE Transactions on Transportation Electrification, 2, 86-95.

46. Emadi, A., Khaligh, A., Rivetta, C. H., \& Williamson, G. A. (2006). Constant power loads and negative impedance instability in automotive systems: Definition, modeling, stability, and control of power electronic converters and motor drives. IEEE Transactions on Vehicular Technology, 55, 1112-1125.

47. Lin, P., Jiang, W., Wang, J., Shi, D., Zhang, C., \& Wang, P. (2021). Toward large-signal stabilization of floating dual boost converter-powered DC microgrids feeding constant power loads. IEEE Journal of Emerging and Selected Topics in Power Electronics, 9(1), 580-589. https://doi.org/10.1109/ JESTPE.2019.2956097

48. Lin, P., Zhang, C., Zhang, X., lu, H. H. C., Yang, Y., \& Blaabjerg, F. (2021). Finite-time large signal stabilization for high power DC microgrids with exact offsetting of destabilizing effects. IEEE Transactions on Industrial Electronics, 68(5), 4014-4026. https://doi.org/10.1109/TIE.2020.2987275

49. Nahata, P., Bella, A. L., Scattolini, R., \& Ferrari-Trecate, G. (2020). Hierarchical control in islanded DC microgrids with flexible structures. In IEEE transactions on control systems technology. https://doi.org/10.1109/TCST.2020. 3038495.

50. Chen, L., Yang, T., Gao, F., Bozhko, S., \& Wheeler, P. (2018). DC microgrid control principles-Hierarchical control diagram. In DC Distribution Systems and Microgrids, vol. 115. T. Dragi" cevi' c, P. Wheeler, and F. Blaabjerg, Eds. London: The Institution of Engineering and Technology, 2018, ch. 1 (pp. 1-21).

51. Vandoorn, T. L., Vasquez, J. C., De Kooning, J., Guerrero, J. M., \& Vandevelde, L. (2013). Microgrids: Hierarchical control and an overview of the control and reserve management strategies. IEEE Industrial Electronics Magazine, 7(4), 42-55. https://doi.org/10.1109/MIE.2013.2279306

52. Pragallapati, N., Ranade, S. J., \& Lavrova, O. (2021). Cyber physical implementation of improved distributed secondary control of DC microgrid. In 2021 1st international conference on power electronics and energy (ICPEE) (pp. 1-5). https://doi.org/10.1109//CPEE50452.2021.9358705.

53. Wang, Y., et al. (2021). A distributed control scheme of microgrids in energy internet paradigm and its multisite implementation. IEEE Transactions on Industrial Informatics, 17(2), 1141-1153. https://doi.org/10.1109/ TII.2020.2976830

54. Li, R., Liu, S., Xia, M., \& Liu, X. (2020). Analysis of effects of communication conditions on distributed secondary control for DC microgrids. In 2020 IEEE 9th international power electronics and motion control conference (IPEMC2020-ECCEAsia) (pp. 2933-2938). https://doi.org/10.1109/IPEMCECCEAsia48364.2020.9368071.

55. Saublet, L., Gavagsaz-Ghoachani, R., Martin, J., Nahid-Mobarakeh, B., \& Pierfederici, S. (2016). Bifurcation analysis and stabilization of DC power systems for electrified transportation systems. IEEE Transactions on Transportation Electrification, 2(1), 86-95. https://doi.org/10.1109/TTE.2016. 2519351

56. Emadi, A., Khaligh, A., Rivetta, C. H., \& Williamson, G. A. (2006). Constant power loads and negative impedance instability in automotive systems: Definition, modeling, stability, and control of power electronic converters and motor drives. IEEE Transactions on Vehicular Technology, 55(4), 1112-1125. https://doi.org/10.1109/TVT.2006.877483 
57. Wu, H., \& Pickert, V. (2014). Stability analysis and control of nonlinear phenomena in bidirectional boost converter based on the Monodromy matrix. In Twenty-ninth annual IEEE applied power electronics conference and exposition (pp. 2822-2827).

58. Cupelli, M., Zhu, L., \& Monti, A. (2015). Why ideal constant power loads are not the worst case condition from a control standpoint. IEEE Transactions on Smart Grid, 6, 2596-2606.

59. Pastore, S., Bosich, D., \& Sulligoi, G. (2016). Influence of DC-DC load converter control bandwidth on small-signal voltage stability in MVDC power systems. In International conference on electrical systems for aircraft railway ship propulsion and road vehicles \& international transportation electrification conference (pp. 1-6).

60. Pastore, S., Bosich, D., \& Sulligoi, G. (2018). An analysis of the small-signal voltage stability in MVDC power systems with two cascade controlled DC-DC converters. In IECON 2018-44th annual conference of the IEEE industrial electronics society (pp. 3383-3388).

61. Pastore, S., Bosich, D., \& Sulligoi, G. (2017). Analysis of small-signal voltage stability for a reduced-order cascade-connected MVDC power system. In Industrial electronics society IECON 2017-43rd annual conference of the IEEE (pp. 6771-6776).

62. Javaid, U., Christe, A., Freijedo, F. D., \& Dujic, D. (2017). Interactions between bandwidth limited CPLs and MMC based MVDC supply. In IEEE energy conversion congress and exposition (ECCE) (pp. 2679-2685).

63. Pastore, S., Bosich, D., \& Sulligoi, G. (2018). A frequency analysis of the small-signal voltage model of a MVDC power system with two cascade DC-DC converters. In IEEE international conference on electrical systems for aircraft railway ship propulsion and road vehicles \& international transportation electrification conference (pp. 1-6).

64. Ma, Y., Corzine, K., Maqsood, A., Gao, F., \& Wang, K. (2019). Stability assessment of droop controlled parallel buck converters in zonal ship DC microgrid. In 2019 IEEE electric ship technologies symposium (ESTS), Washington, DC, USA (pp. 268-272). https://doi.org/10.1109/ESTS.2019. 8847795

65. Jia, L., Du, C., Zhang, C., \& Chen, A. (2017). An improved droop control method for reducing current sensors in DC microgrid. In 2017 Chinese automation congress (CAC), Jinan (pp. 4645-4649). https://doi.org/10. 1109/CAC.2017.8243599

66. Korompili, A., \& Monti, A. (2017). Analysis of the dynamics of dc voltage droop controller of DC-DC converters in multi-terminal dc grids. In 2017 IEEE second international conference on DC microgrids (ICDCM), Nuremburg, 2017 (pp. 507-514). https://doi.org/10.1109//CDCM.2017.8001094.

67. Liu, Y., Han, Y., Lin, C., Yang, P., \& Wang, C. (2019). Design and implementation of droop control strategy for DC microgrid based on multiple DC/ DC converters. In 2019 IEEE innovative smart grid technologies-Asia (ISGT Asia), Chengdu, China, 2019 (pp. 3896-3901). https://doi.org/10.1109/ ISGT-Asia.2019.8881129

68. Gao, F., \& Bozhko, S. (2016). Modeling and impedance analysis of a single DC bus-based multiple-source multiple-load electrical power system. IEEE Transactions on Transportation Electrification, 2, 335-346.

69. Gao, F. (2017). Comparative stability analysis of droop control approaches in voltage source converters-based dc microgrids. IEEE Transactions on Power Electronics, 32, 2395-2415

70. Gao, F., Bozhko, S., Costabeber, A., Asher, G., \& Wheeler, P. (2017). Control design and voltage stability analysis of a droop-controlled electrical power system for more electric aircraft. IEEE Transactions on Industrial Electronics, 64, 9271-9281.

71. Wu, H., Pickert, V., Ma, M., Ji, B., \& Zhang, C. (2020). Stability study and nonlinear analysis of DC-DC power converters with constant power loads at the fast timescale. IEEE Journal of Emerging and Selected Topics in Power Electronics, 8(4), 3225-3236. https://doi.org/10.1109/JESTPE.2020.2966375

72. Xu, Q., Yan, Y., Zhang, C., Dragicevic, T., \& Blaabjerg, F. (2020). An offset-free composite model predictive control strategy for DC/DC buck converter feeding constant power loads. IEEE Transactions on Power Electronics, 35(5), 5331-5342. https://doi.org/10.1109/TPEL.2019.2941714

73. Rahimi, A. M., Khaligh, A., \& Emadi, A. (2006). Design and Implementation Of An Analog Constant Power Load For Studying Cascaded Converters. In IECON 2006 - 32nd annual conference on IEEE industrial electronics, 2006 (pp. 1709-1714). https://doi.org/10.1109/IECON.2006.347635.

74. Arora, S., Balsara, P. T., \& Bhatia, D. K. (2016). Digital implementation of constant power load (CPL), active resistive load, constant current load and combinations. IEEE Dallas Circuits and Systems Conference (DCAS), 2016, 1-4. https://doi.org/10.1109/DCAS.2016.7791138

75. Bengston. T. R. (1997) Constant power load needs only a few parts. Available http://electronicdesign.com/power/constant-power load-needs-only-few-parts.

\section{Submit your manuscript to a SpringerOpen ${ }^{\odot}$ journal and benefit from:}

- Convenient online submission

- Rigorous peer review

- Open access: articles freely available online

- High visibility within the field

- Retaining the copyright to your article

Submit your next manuscript at $\boldsymbol{\nabla}$ springeropen.com 